\title{
PENERIMAAN NILAI - NILAI SOFT POWER MELALUI SERIAL DRAMA INDIA OLEH KHALAYAK INDONESIA
}

\author{
Putu Titah Kawitri Resen ${ }^{1)}$ \\ Ade Devia Pradipta 2) \\ Fakultas Ilmu Sosial dan Ilmu Politik,Universitas Udayana ${ }^{1}$ \\ email: kawitriresen@unud.ac.id \\ Fakultas Ilmu Sosial dan Ilmu Politik, Universitas Udayana ${ }^{2}$ \\ email: deviapradipta88@unud.ac.id
}

\begin{abstract}
ABSTRAK
Tulisan ini bertujuan untuk menggambarkan pengunaan serial drama sebagai instrument soft power, khususnya serial drama India yang ditayangkan di saluran televisi nasional Indonesia. Tujuan khusus dari tulis an ini adalah untuk meng gali opini khalayak Indonesia sehingga dapat diketahui seberapa jauh daya tarik serial drama sebagai instrumen soft power. Tulisan ini merupakan penelitian deskriptif kualitatif menggunakan metode pengumpulan data melalui studi pustaka dan wawancara. Informan ditentukan melalui teknik purposive dan snowball sampling. Menggunakan konsep soft power, penelitian inimenemukan bahwa meskipun serial drama India dinilai cukup menarik oleh khayalak Indonesia, namun tidak semua serial drama India mampu membangun citra positif terhadap India. Serial drama yang mengandung nilai high culture yang lebih dapat membangun citra postif terhadap negara tersebut.
\end{abstract}

Kata kunci: India, Indonesia, khalayak, serial drama, soft power

\begin{abstract}
This article aims at describing the use of drama series as an instruments of soft power, particularly Indian drama series which were aired in Indonesian national television channels. The specific objective of this study is to examine the opinion of Indonesian audiences toward the attractiveness power of the drama series as an instrument of soft power. This research is a descriptive qualitative research using literature study and in depth - interview method. Informants in this study were determined through purposive technique and snowball sampling. Using the concept of soft power, this study found that eventhough Indian drama series are considered quite attractive by Indonesian audiences, not all Indian drama series are able to build a positive image of India. Only the drama series which contains high culture values can build positive image of the country.

Keyword: India, Indonesia, audiences, drama series, soft power
\end{abstract}

\section{PENDAHULUAN}

Penggunaan soft power dalam kebijakan luar negeri India bukanlah hal yang baru. Sebelum kemerdekaan India, Mahatma Gandhi telah merepresentasikan nilainilai filosofis perdamaian India yang menjadi salah satu sumber soft power India. Paska kemerdekaan, Indiapun menginvestasikan sumber dayanya melalui beberapa cara, yaitu seperti dialog tingkat tinggi, pertukaran intelektual dan budaya, konferensi - konferensi, serta diplomasi terbuka oleh pemerintah. Di bawah pemerintahan Perdana Menteri Narendra Modi, India mengeluarkan sebuah gerakan 
yang disebut dengan Make in India untuk menggencarkan penggunaan soft power melalui nilai-nillai tradisi, kebudayaan kuno, filosofi, serta identitas religijus India ke dunia internasional dalam kerangka diplomasi budaya ( Mahapatra, 2016 ). Diungkapkan oleh Mapatra ( 2016 ), Perdana Menteri Narendra Modi memahami pentingnya menjalin hubungan baik dengan negara - negara tetangga jika India ingin menjadi kekuatan besar di kancah global melalui dengan menggunakan potensi potensi soft power yang dimiliki India, terutama dengan budaya sebagai perantaranya.

India memiliki sumber soft power yang sangat melimpah mulai dari budaya multietnis, nilai-nilai agama, filosofi yang mengedepankan perdamaian, beragam karya seni yang unik serta karya sastra ( T. V. Paul, 2014 : ). Selaras dengan pendapat tersebut, Mahapatra ( 2016 ) memberikan contoh sumber-sumber soft power India yang sudah dikenal di seluruh dunia salah satunya adalah yoga, sebuah seni olah jiwa dan raga. Perserikatan Bangsa-bangsapun menetapkan tanggal 21 Juni sebagai Hari Yoga Internasional karena antusiasme masyarakat dunia untuk mempraktikan perpaduan seni dan olah jiwa raga ini. Selain Yoga, Ayurveda juga menjadi sumber soft power bagi India. Ayurveda adalah sebuah kitab yang memuat ilmu pengobatan yang menggunakan bahan - bahan dari alam beserta teknik pengobatannya telah diakui di dunia internasional dan menjadi salah satu acuan bagi dunia kesehatan Barat. Bollywood, industri perfilman India adalah aset soft power India yang dinikmati dan digemari di beberapa negara antara lain Afghanistan, Pakistan, Asia Tengah dan Asia Tenggara dan didukung pula dengan berbagai serial drama atau opera sabun India. Masih banyak lagi sumber soft power lainnya seperti makanan India yang bisa dinikmati di restoran-restoran India di seluruh dunia dan demokrasi ala India yang menjadi karakter India sejak masa kemerdekaannya.

Serial drama India yang menjadi salah satu aset soft power bagi negara tersebut adalah fokus dalam tulisan ini. Perkembangan teknologi satelit dan televisi menyebabkan film dan serial drama menjadi alat untuk memperkenalkan budaya dan masyarakat India pada masyarakat global. Tahun 1990-an menjadi masa awal ketika saluran televisi nasional Indonesia dibanjiri dengan beragam serial drama asal India. Serial Mahabharata dan Ramayana yang tayang di awal tahun 1990an misalnya, menjadi tontonan favorit keluarga Indonesia pada waktu itu. Popularitas serial drama India memang mengalami pasang surut akibat munculnya tayangan serupa dari negara lain misalnya Jepang dan Korea, namun hingga saat ini saluran televisi Indonesia masih terus menayangkan beberapa judul serial drama asal negara yang dijuluki Anak Benua tersebut.

Soft power sebuah konsep yang digagas oleh Joseph S. Nye, JR dapat didefinisikan sebagai kemampuan untuk mendapatkan apa yang kita inginkan lewat daya atraktif daripada menggunakan paksaan atau pemberian imbalan.( Nye JR, 2004 : x). Soft power sebuah negara merupakan daya pikat negara tersebut yang bersumber dari budayanya, idealisme politik, dan kebijakan luar negeri yang membuat negara tersebut memiliki legitimasi dan otoritas moral. Nye ( 2004 ) 
memberikan contoh bahwa idealisme Amerika Serikat seperti demokrasi, hak asasi manusia, kebebasan individu telah lama menjadi sumber power yang menggoda hampir setiap individu di seluruh belahan dunia dan membuat Amerika dikagumi.

Budaya sebagai sumber soft power, oleh Nye Jr (2004) dideskripsikan dengan lebih komprehensif sebagai seperangkat nilai dan kebiasaan yang menciptakan makna bagi masyarakat dalam berbagai manifestasinya. High culture dapat berupa karya sastra, karya seni, dan pendidikan yang menarik baik kaum elit, sedangkan popular culture dapat berupa hiburan massal ( mass entertainment) yang dapat dikemas dalam berbagai jenis. Ketika budaya sebuah negara mengandung nilai- nilai universal dan kebijakan yang dibuat negara tersebut menjadi kebutuhan negara negara lain, maka negara bersangkutan dapat dengan mudah mencapai apa yang menjadi tujuannya. Nye Jr ( 2004 ) memberikan ilustrasi bahwa letak daya pikat Amerika Serikat pada beberapa faktor seperti teknologi dan ilmu pengetahuan, musik, film, acara televisi, nilai demokrasi Amerika, perilaku bisnis ala Amerika, serta ide-ide dan kebiasaaan orang Amerika membuat Amerika begitu dikagumi dan dampaknya adalah Amerika Serikat bukan saja menjadi negara dengan tingkat ekonomi tertinggi di dunia, setengah dari 500 perusahaan global adalah perusahaan Amerika, serta 62 dari 100 merk global berasal dari Amerika Serikat. Tidak hanya Amerika Serikat, negara negara lain seperti Rusia, Jerman, Perancis, Inggris, dan Jepang juga mengembangkan nilai-nilai mereka yang dapat menjadi sumber soft power.

Penggunaan soft power melibatkan referees yaitu pihak yang menjadi sumber rujukan legitimasi dan kredibilitas dan receivers yang merupakan target atau sasaran yang dituju seperti yang tercantum dalam tabel berikut.

\section{SOFT POWER SOURCES, REFEREES, AND RECEIVERS}

\begin{tabular}{lcl}
\hline $\begin{array}{l}\text { Sources of Soft } \\
\text { Power }\end{array}$ & \multicolumn{1}{c}{$\begin{array}{c}\text { Referees for Credibility } \\
\text { or Legitimacy }\end{array}$} & Receivers of Soft Power \\
\hline Foreign policies & $\begin{array}{c}\text { Governments, media, nongovernmental } \\
\text { organizations (NGOs), intergovernmental } \\
\text { organizations (IGOs) }\end{array}$ & $\begin{array}{c}\text { Foreign governments } \\
\text { and publics }\end{array}$ \\
$\begin{array}{l}\text { Domestic values } \\
\text { and policies }\end{array}$ & Media, NGOs, IGOs & $\begin{array}{c}\text { Foreign governments } \\
\text { and publics }\end{array}$ \\
$\begin{array}{l}\text { High culture } \\
\text { Pop culture }\end{array}$ & Governments, NGOs, IGOs & $\begin{array}{c}\text { Foreign governments } \\
\text { and publics }\end{array}$ \\
\hline
\end{tabular}

Sumber : Nye, Jr.. ( 2008 ). Hlm. 107

Pop culture melibatkan hubungan antara media dan pasar sebagai referees dengan 
publik atau masyarakat negara lain sebagai receivers atau penerima. Dengan demikian, serial drama sebagai salah satu wujud pop culture bergantung dari penerimaan khalayak dari negara lain untuk dikatakan mampu mempromosikan kepentingan negara asal dan mencapai hasil yang diinginkan. Serial drama India sebagai sebuah pop culture sangatlah mudah diakses oleh khalayak di Indonesia dan memiliki jam tayang yang cukup tinggi di saluran-saluran televisi swasta di Indonesia. Namun demikian, seberapa jauh aset - aset soft power India yang telah mendunia tersebut membantu India mewujudkan tujuan-tujuannya masih perlu dikaji lebih lanjut ( Mahapatra, 2016 ). Oleh karena itulah tulisan ini ingin menjawab bagaimana penerimaan nilai-nilai soft power yang terkandung dalam serial drama India oleh khalayak Indonesia.

\section{METODE PENELITIAN} dan

Penelitian ini adalah penelitian deskriptif kualititatif dengan metode studi pustaka depth-interview. Data dalam studi ini didapatkan melalui penelusuran dokumen dan referensi berupa jurnal maupun buku serta dari hasil wawancara secara mendalam dengan 15 orang penggemar serial drama televisi India yang rata-rata telah menonton 7 serial drama India. Subyek studi ditentukan dengan teknik purposive dan snowball sampling agar mendapatkan informasi yang mendalam mengenai opini mereka terhadap serial drama asal India yang ditayangkan di televisi nasional Indonesia. Analisis data dalam studi ini dimulai dengan reduksi data, penyajian data, dan penarikan kesimpulan. Reduksi data dilakukan untuk melakukan seleksi data yang relevan agar mampu mencapai tujuan studi. Penyajian data dilakukan secara deskriptif kualitatif untuk menggambarkan data secara keseluruhan. Terakhir, penarikan kesimpulan dilakukan secara induktif melalui pencarian hubungan antar data yang telah dikumpulkan ( Yusuf, 2014:400 ).

\section{PEMBAHASAN}

\section{Serial Drama India di Televisi Nasional Indonesia}

Beberapa judul serial drama asal India seperti Mahabrata, Jodha Akbar, Asoka, Uttaran Lonceng Cinta dan berbagai judul lainnya memenuhi layar kaca Indonesia. Nama-nama seperti Rajat Tokas dan Paridhi Sarma yang bermain di serial Jodha Akbar, Tinna Dutta dan Nandhis Shandu yang berperan dalam serial Uttaran, Shaheer Sheikh, Pooja Sharma, Rohit Bharadwaj, Lavanya Bhardwaj, Vin Rana, dan Arav Chowdhary pemeran dalam serial Mahabharata tidak asing ditelinga penggemar serial drama tersebut. Kecintaan terhadap serial drama asal juga nampak saat para aktor tersebut berkunjung ke Indonesia untuk berjumpa secara langsung dengan para penggemar mereka (https://www.viva.co.id/arsip/543697-invasi-mahabharata). Hal ini membuktikan bahwa serial drama asal India digemari oleh masyarakat Indonesia, khususnya para ibu dan remaja perempuan.

Gambar 1. Pemeran Serial Mahabharata saat berkunjung ke Jakarta 


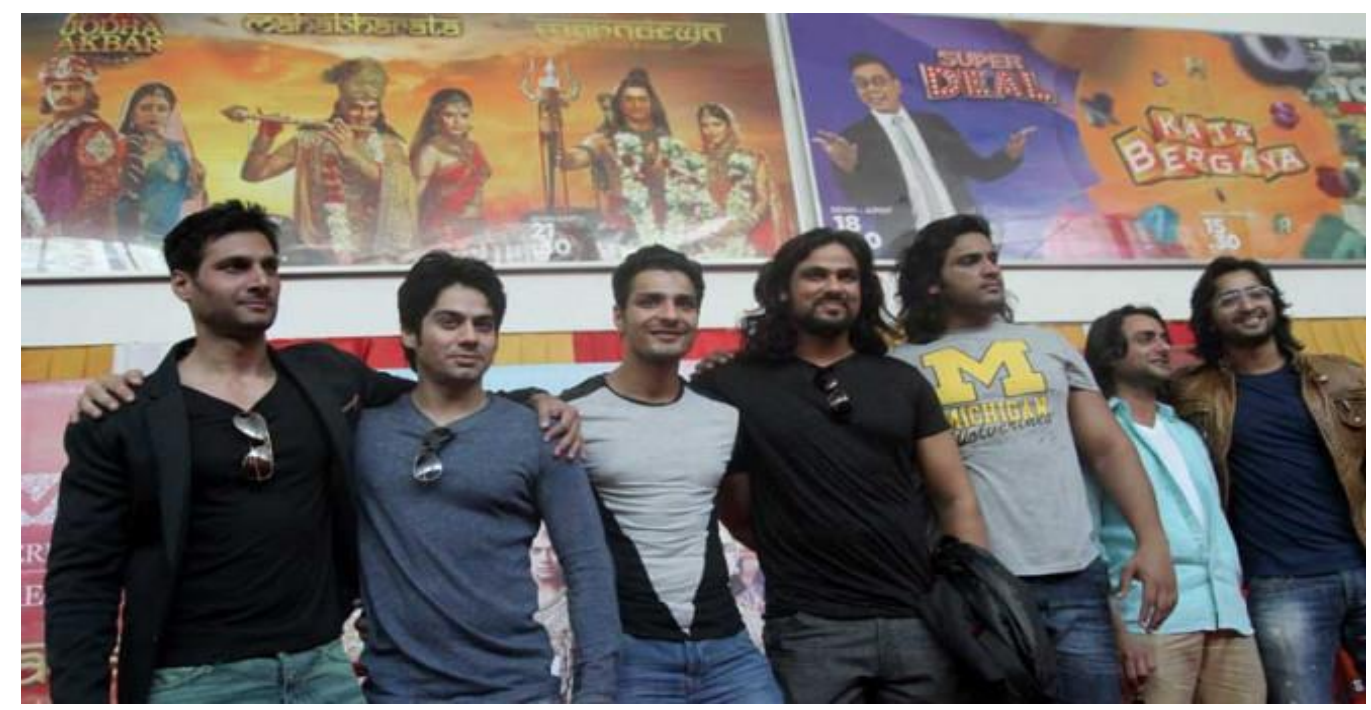

Sumber : https://www.viva.co.id/arsip/543697-invasi-mahabharata

Tayangan - tayangan asal India baik film maupun serial drama telah lama memenuhi layar kaca Indonesia. Untuk mengetahui perkembangan tayangan serial drama India di saluran televisi Indonesia, sebuah penelitian menarik oleh Melisa Indriani Putri ( 2015 ) dapat menjadi sumber acuan yang komprehensif. Putri ( 2015 ) menggambarkan istilah pasang surut perkembangan tayangan televisi India di serial televisi Indonesia dengan sebutan siklus Indianisasi. Siklus Indianisasi ini dapat dibagi kedalam tiga periode. Tahun 1991-1998 merupakan siklus pertama Indianisasi, diikuti dengan siklus kedua dari tahun 2001-2003, dan siklus ketiga dimulai sejak tahun 2014. Siklus pertama ini ditandai dengan hadirnya serangkaian tayangan serial India yang menceritakan epos-epos kuno, seperti Mahabharata dan Ramayana yang bersifat kolosal. Tercatat bahwa serial Mahabharata tayang untuk pertama kalinya di televisi Indonesia pada 7 Desember 1991 pukul 11.00-12.00 WIB setiap hari Sabtu. Penayangan Mahabharata yang mendapatkan respon baik oleh pemirsa di Indonesia kemudian diikuti oleh penayangan serial Ramayana yang juga menuai kesuksesan. Satu serial lagi yaitu Panglima Chanakya yang tayang setelah serial Ramayana tamat tidak menuai kesuksesan seperti dua serial mitologi sebelumnya. Pada siklus kedua yang dimulai dari tahun 2001-2003 didominasi oleh film-film India daripada tayangan serial drama televisi. Film-film India yang berjaya dan mampu menyedot penonton Indonesia kala itu antara lain Kuch Kuch Hota Hai yang menjadi momentum siklus Indianisasi yang kedua. Beberapa judul film India lainnya yang tayang di televisi Indonesia adalah Chalte Chalte, Hum Tumhare Hain Sanam, Mohabbatein, Bewafaa, Main Hoon Na, Kyun Ho Gaya Na, Veer Zaara, Black, Dhoom, Dil Mange More, Bunty Aur Babli, Salaam Namaste, Mujhse Dosti Karoge, Dil To Pagal Hai, Koi Mil Gaya, Dilwale Dulhania Le Jayenge, dan Kaho Na Pyaar Film-film ini kebanyakan dibintangi oleh Shahrukh Khan, Abhishek Bachchan, Preity Zinta, Rani Mukherjee, Aishwarya Rai, dan Amitabh Bachchan. Pada siklus yang ketiga, serial Mahabharata dan Ramayana versi modern kemIndonesia menjadi penanda kebangkitan serial drama 
India di televisi Indonesia yang mulai tayang di tahun 2014. Berbagai judul serial menarik lainnyapun menyusul untuk tayang di televisi Indonesia seperti Mahadewa, Jodha Akbar, Shakuntala, Krishna, dan serial modern Navya.

Berdasarkan wawancara dengan para informan dalam penelitian ini, beberapa judul tayangan serial drama India yang digemari oleh khalayak Indonesia tercantum dalam tabel berikut :

Tabel 2. Daftar Drama India (Bollywood) yang Ditonton oleh Informan Penelitian

\begin{tabular}{|c|c|c|c|}
\hline No & Judul Drama & Tahun Tayang & Stasiun TV \\
\hline 1 & $\begin{array}{l}\text { Ye Hai Mohabbatein } \\
\text { - Tayang di RCTI dengan Judul } \\
\text { "Ruhi Tersayang" } \\
\text { - Tayang di ANTV dengan judul } \\
\text { Mohabbatein }\end{array}$ & 2015,2016 & RCTI, ANTV \\
\hline 2 & Jodha Akbar & 2015,2017 & ANTV, MNC TV \\
\hline 3 & Mahabrata & $2014,2017,2019$ & ANTV, MNC TV \\
\hline 4 & Asoka & 2015,2019 & ANTV, MNCTV \\
\hline 5. & Uttaran & 2015 & ANTV \\
\hline 6 & Anandhi & 2016 & ANTV \\
\hline 7 & Candra Nandini & 2018 & ANTV \\
\hline 8 & Shakuntala & 2015 & ANTV \\
\hline 9 & Gopi & 2016 & ANTV \\
\hline 10 & Thapki & 2016,2017 & ANTV \\
\hline 11 & Lonceng Cinta & 2016 & ANTV \\
\hline 12 & Beintehaa & 2015 & ANTV \\
\hline 13 & Baal Veer & 2012 & ANTV \\
\hline 14 & Archana Mencari Cinta & 2009 & ANTV \\
\hline 15 & Geet & 2010 & ANTV \\
\hline 16 & Kaali dan Gauri & 2016 & ANTV \\
\hline 17 & Mahaputra & 2013 & ANTV \\
\hline 18 & Punar Vaivah & 2017 & ANTV \\
\hline 19 & Pyar Ka Dard & 2014 & ANTV \\
\hline 20 & Ramayana & 2014 & ANTV \\
\hline 21 & Naagin & 2016 & SCTV \\
\hline
\end{tabular}

Sumber : Olah Data Penelitian

Dari data diatas ditemukan bahwa sejak tahun 2014, serial drama India semakin intens silih berganti tayang di saluran televisi nasional, meskipun ada beberapa judul yang ditayangkan sebelum tahun 2014 misalnya Ball Veer yang tayang di tahun 2012 dan Archana Mencari Cinta yang tayang di tahun 2009. ANTV adalah saluran televisi 
yang paling sering menayangkan serial drama asal India, namun demikian beberapa saluran televisi lainnya pun turut menghadirkan serial drama India sebagai salah satu program tayangan televisi mereka.

\section{Penerimaan Serial Drama India sebagai Instrumen Soft Power oleh Khalayak Indonesia}

\section{a. Daya Tarik Serial Drama India}

Kekuatan soft power terletak pada daya pikat (attractiveness). Penggemar serial drama sebagai receivers atau penerima memegang peranan penting untuk melihat sejauh mana mereka menerima nilai-nilai yang dipromosikan melalui penggunaan aset soft power atau, merujuk pada Nye ( 2004 ), digunakan sebagai sebuah perkiraan awal untuk mengetahui seberapa menariknya sebuah negara. Ada tiga hal yang menjadi daya tarik serial drama India berdasarkan hasil wawancara dengan para informan yaitu kedekatan kultural, kedekatan kondisi sosial masyarakat, dan daya tarik aktor atau pemain dalam serial drama tersebut. Ketiga hal inilah yang menjadikan serial drama India digemari oleh khalayak Indonesia.

Daya tarik yang pertama bergantung pada kedekatan kultural yang diungkapkan oleh Nye ( 2004 ) bahwa " popular culture is more likely to attract people and produce soft power in the sense of preferred outcomes in situations where cultures are somewhat similar rather than widely dissimilar ". Ini berarti bahwa penerimaan nilainilai soft power akan lebih mudah terjadi diantara negara-negara yang memiliki kedekatan dan persamaan budaya, tradisi, dan norma-norma tertentu. Menurut Putri ( 2015 ) kondisi sosial budaya Indonesia yang terbentuk sejak masa lampau diwarnai dengan keragaman budaya mendapat pengaruh dari Tiongkok, Arab, Melayu dan juga India dan telah mengalami alkuturasi. Akulturasi budaya India di Indonesia misalnya bisa dilihat dalam kehidupan sehari -hari mulai dari bisa penggunaan nama dan istilah -istilah Sansekerta di masyarakat Indonesia, pengaruh pada arsitektur dan juga karya sastra India yang diadaptasi di Indonesia.

Selanjutnya, hasil wawancara dengan informan dalam tulisan ini mendukung alasan kedekatan budaya sebagai salah satu faktor daya tarik serial drama asal India tercantum dalam kutipan wawancara berikut :

"Sebenarnya tema dari serial drama India cukup beragam. Ada drama percintaan, konflik ibu mertua dan menantu, ya mirip-miriplah dengan sinetron Indonesia. Tapi kita juga sekaligus belajar mengenai sejarah, mengenai agama, mengenai pewayangan juga. Ya itu... Hindu kan agama tertua yang ada di Indonesia, ya. Yang bagus dari sinetron India adalah drama sejarah dan agama seperti Mahabharata, Mahadewa, Asoka, Chandra Gupta, Ramayana, Jodha Akbar" (Wawancara dengan Ratna, 27 Juli 2019).

Melalui serial drama ini, khalayak Indonesia bisa mengenal dan mengingat kembali tokoh-tokoh dan jalan cerita dalam kisah pewayangan Mahabharata dan Ramayana. Dialog antara Arjuna dengan Sri Krishna yang tertulis dalam Bhagavad Gita dipelajari 
dengan lebih mudah oleh khalayak melalui peran yang dimainkan oleh aktor-aktor dalam serial drama tersebut. Selain itu, masyarakat India yang majemuk juga memiliki kemiripan dengan masyarakat multikultur di Indonesia yang menjadi daya tarik kedekatan budaya seperti diuraikan oleh salah satu informan :

" Masyarakat di India sangat beragam, lihat dari agamanya saja ada Islam, Hindu, Buddha, Sikh dan Indonesia juga memiliki keragaman itu, ada Islam, Hindu, Budha, Kristen...Ada kisah yang mengangkat tema Buddha, ada kisah yang mengangkat tema Hindu,ada cerita yang mengangkat konflik atau kerukunan antar agama. Di satu sisi, kita gampang mengikuti jalan ceritanya karena kemiripan masyarakat kita, di sisi yang lain kita juga bisa belajar tentang penyebab konflik ataupun belajar cara menciptakan kerukunan di masyarakat yang majemuk, Kita seperti bercermin pada diri kita (Wawancara dengan Kristin, tanggal 7 Juli 2019).

Daya tarik yang kedua yaitu dari kemiripan situasi sosial yang dihadirkan dalam cerita serial drama India. Tema kehidupan sehari-hari, kesenjangan antara si kaya dan miskin, konflik rumah tangga di Indonesia dan sebagainya. Salah satu kemiripan dalam situasi sosial tersebut dapat dilihat dari kutipan wawancara berikut :

"Walaupun beberapa cerita agak lebay ya, tapi menarik juga. Yah..ternyata dimana-mana sama aja ya. Ibu mertua susah akur sama menantu perempuan, he he. Kalau nggak sama mertua, ya bisa aja berkonflik dengan ipar, kan. Sama saja seperti kita. Apalagi lihat tuh...kalau di sinetron India itu kayaknya satu keluarga tinggal dalam keluarga besar dalam satu rumah. Duh bayangkan, kita harus seatap dengan orang yang tidak suka sama kita. Suka kasihan aja sama tokoh yang merana, jadi kayak membayangkan itu terjadi pada diri kita he he", (wawancara dengan Nastari,14 Juli 2019).

Ada juga informan yang menyoroti persamaan kondisi India dengan Indonesia berdasarkan kondisi kesenjangan ekonomi yang serupa seperti diungkapkan berikut:

"India sama Indonesia mungkin mirip kondisi masyarakatnya, ada kesenjangan antara yang kaya dan miskin. Seperti Icha dan Tapasya di Uttaran. Buat saya menarik saja sih cerita begitu. Mungkin itu yang bikin drama India ini menarik, mirip gitu dengan kondisi di masyarakat kita. Yang kaya ada, yang miskin banyak..ha..ha..ha... " (Wawancara dengan Kartika, tanggal 7 Juli 2019)

Terakhir, selain kemiripan budaya dan kondisi sosial, para pemain atau pemeran serial drama India juga menjadi salah satu daya tarik serial drama tersebut bagi khalayak di Indonesia. Diplomasi publik sebagai sarana penyebaran soft power tidak hanya melibatkan pemerintah, namun juga aktor lain seperti organisasi non pemerintah, perusahaan, media, dan bahkan individu memainkan peran besar seperti yang 
dinyatakan oleh Nye (2004) "Much of American soft power has been produced by Hollywood, Harvard, Microsoft, and Michael Jordan". Dalam serial drama Indiapun, kekaguman terhadap para pemeran atau aktor menjadi salah satu pemikat yang tak dapat dielakkan. Ketampanan dan kecantikan para aktor, selain kemampuan akting para pemeran tersebut dapat menjadi alasan mereka untuk terus mengikuti serial drama lainnya dimana aktor idola mereka turut bermain dalam serial drama tersebut.

"Kalau Shaheer Sheikh yang main, ya pasti nonton lah..... Ada banyak sih yang favorit Vin Rana juga idola saya, Manish Goplani, hmmm itu yang jadi Sri Krishna juga eh... Saurabh Raj Jain. Kalau yang cewek sih...Pooja Sharma " (Wawancara dengan Dian, 15 Juli 2019).

Kutipan wawancara menjadi sebagian ungkapan kekaguman para penggemar pada para pemeran serial drama tersebut. Tidak menjadi hal yang aneh ketika para penggemar tersebut memiliki cita-cita untuk bertemu langsung dengan para aktor idola mereka.

\section{b. Citra India melalui Serial Drama}

Soft power dikatakan kuat jika nation branding, sebuah upaya negara membentuk opini internasional, berhasil membentuk citra yang baik dan menyenangkan di mata khalayak internasional. Hal ini akan menjadi sebuah keuntungan kompetitif bagi negara misalnya memiliki keunggulan dalam bidang pariwisata dan mampu menarik investasi asing. Namun demikian, soft power bisa menjadi sangat subyektif karena didasarkan atas opini publik tersebut. Ditegaskan oleh Fang ( 2008 ) : As soft power rests on attraction, the power lies not in the hand of the party who possesses it, but in the response and reaction of the party who receives itu. Oleh karena itu, soft power bisa menjadi lemah jika citra yang terbentuk melalui nation branding tersebut kurang positif di mata khalayak. Serial drama India yang dikonsumsi di Indonesia membentuk citra India di mata khalayak. Beberapa serial drama membantu terbentuknya citra positif India, namun ada juga beberapa hal dalam serial drama yang kurang mendukung pembentukan citra positif tersebut.

Citra positif yang pertama yang terbentuk melalui serial drama adalah India sebagai tempat tujuan wisata yang indah dan penuh sejarah. Menurut hasil wawancara, drama bertema sejarah banyak memberikan kesan positif pada India. Ketenaran serial drama Jodha Akbar yang tayang di tahun 2015 dan 2017 misalnya, membangkitkan keinginan untuk berkunjung ke salah satu situs keajaiban dunia Taj Mahal (Wawancara dengan Yunita, 5 Agustus 2019). Serial Jodha Akbar adalah serial drama yang mengisahkan kisah cinta antara Raja Mughal dengan Putri Jodha yang beragama Hindu dan kisah cinta tersebut menjadi cikal bakal berdirinya bangunan megah Taj Mahal sebagai lambang cinta sang raja kepada istrinya tersebut. Serial lainnya yang juga menggugah minat khalayak untuk mengunjungi atau berwisata ke India adalah serial Mahabharata yang berlatar di Kurukshetra seperti kutipan wawancara berikut:

"Pengen banget pergi ke India. Karena nonton Mahabharata, Mahadeva ingin 
juga tau kuil-kuil disana seperti apa. Pingin tirta yatra, tapi yah nunggu, nabung dulu supaya bisa beli paket paket tur. Perginya bareng sama suami" ( Wawancara dengan Juni, 14 Agustus 2019).

Citra positif yang kedua adalah terkait kandungan nilai-nilai moral dan kekayaan budaya yang ditampilkan dalam serial drama India. Agama telah menjadi bagian penting dari budaya India dimana empat agama besar lahir yaitu Hindu, Budha, Jain, dan Sikh. Serial drama yang berlatar relijius dan perjuangan mampu mengundang kekaguman dari khalayak baik karena sejarahnya maupun karena kandungan nilai-nilai kebaikan yang diselipkan dalam tayangan tersebut. Salah seorang informan menyampaikan opininya sebagai berikut:

"Banyak pelajaran juga yang bisa kita petik melalui sinetron India. Intinya sih kebahagiaan pasti akan datang bagi yang selalu berbuat baik. Hidup ini adalah pertarungan antara kebaikan dan kejahatan, dan akhirnya kebaikan akan selalu menang. Menjadi pengingat kita untuk selalu berbuat kebaikan dalam hidup dan pantang menyerah. Saya paling suka wejangan Sri Krishna setiap awal episode, perjuangan Rama dan istrinya dengan tabah ketika dibuang ke hutan, kemenangan Asoka yang sebelumnya diasingkan, perjuangan Anandhi untuk terus semangat belajar, perjuangan Thapki agar bisa diterima dalam pergaulan..." (wawancara dengan Sri, tanggal 26 Agustus 2019).

Informan lain memberikan opininya terhadap serial drama India sebagai berikut:

"Sinetron India, budaya Indianya kental sekali. Pakaian tradisional itu dipakai mereka sehari-hari.Meskipun di era modern saat ini, sepertinya mereka masih memegang teguh pakaian tradisional mereka. Nilai-nilai penghormatan kepada orangtua atau nilai bagaimana yang tua mengajarkan yang muda juga ada di serial drama India" (wawancara dengan Devi, tanggal 2 Agustus 2019)

Kentalnya budaya dan tradisi India yang ditampillan dalam serial drama menjadi contoh bagaimana India menyatukan tradisi dengan modernitas yang menjadi sumber kekaguman oleh khalayak di Indonesia.

Namun, terdapat pula hal-hal yang berdasarkan opini khalayak di Indonesia kurang mendukung terbentuknya citra positif terhadap India dalam serial drama. Salah satunya adalah serial drama India kurang bisa mencerminkan India secara nyata seperti pendapat yang dikutip dibawah ini:

"Serial drama India tidak cukup menggambarkan India sebagai negara. Drama India kurang mengeksplor pemandangan kota, alam, dan pedesaan jika dibandingkan dengan drama Korea. Jika tema dramanya adalah 
mengenai keluarga, settingnya selalu di rumah besar dengan banyak penghuninya, ada kakek nenek, paman dan bibi, orang tua kita, saudara sepupu yang sudah menikah dengan anak - anaknya. Konflik terpusat disana dan setting film (drama) selalu disana (di rumah tersebut)" (wawancara dengan Jovi, 9 Agustus 2019).

Beberapa serial drama dengan tema percintaan masa kini dianggap sebagai hiburan semata. Alur yang panjang dengan cerita yang kompleks serta membuat rasa penasaran khalayak terjaga untuk tetap menonton serial drama tersebut sampai selesai, namun tidak cukup membangun citra positif bagi India.

"Drama India biasanya ceritanya berbelit - belit, ketika satu tokoh jahat mati, akan muncul lagi tokoh jahat yang lain. Ndak habis-habis. Bagus ceritanya dan bisa bikin ikut nangis. Mudah-mudahan sikap-sikap jahat tidak sampai ditiru di dunia nyata ya", (wawancara dengan Purnama, tanggal 25 Agustus 2019).

Ada pula pendapat dari informan yang menyatakan bahwa India lebih diresepresentasikan lewat film-film layar lebar daripa lewat serial drama India.

"Kalau mau tahu India, lebih baik lewat film-filmnya. Lebih menggambarkan India yang real daripada lewat serial drama. Coba tonton Slumdog Millionaire. Saya suka film India, juga suka drama-drama India di tv. Kalau sinetron-sinetron ini kan buat tontonan aja supaya nggak suntuk. Kalau ngikutin dari awal, ya pingin ngikutin sampai habis ceritanya", (wawancara dengan Puspita, pada tanggal 26 Agustus 2019).

Pendapat-pendapat diatas menggambarkan subyektivitas penilaian soft power seperti yang diungkapkan oleh Fang ( 2008 ). Meskipun secara umum serial drama India dipandang atraktif, kekayaan sumber soft power melalui serial drama India lebih banyak didukung oleh serial drama yang bertemakan sejarah dan epos yang sarat akan nilai moral dan kandungan high culture berupa nilai filosofis, karya seni dan sastra. Serial drama dengan tema percintaan dan konflik keluarga tetap menarik bagi khalayak namun kurang mendukung terbangunnya citra positif terhadap India karena berfungsi sebagai hiburan semata.

\section{SIMPULAN}

Penggunaan sumber soft power untuk mencapai tujuan nasional bergantung pada penerimaan receivers publik negara lain. Semakin positif citra negara yang dibangun oleh instrumen yang digunakan, semakin kuat pula soft power negara tersebut. Serial drama India merupakan salah satu instrumen soft power India yang membanjiri tayangan televisi di Indonesia. Bagi khalayak, daya atraktif serial drama India terletak pada 3 hal yaitu kedekatan kultural, kedekatan kondisi sosial, dan faktor 
pemeran atau pemain serial drama tersebut. Namun demikian, tidak semua serial drama India mampu membangun citra positif bagi negara tersebut. Kandungan nilai-nilai high culture dalam serial drama yang bertemakan sejarah, keagamaan, dan epos klasik lebih bisa membangun citra positif bagi India.

\section{Referensi}

Fan, Ying. 2008. Soft Power : Power of Attraction or Confusion? Place Branding and Public Diplomacy. No 4 : 2, hlm. 147-158

Mahapatra, Debidatta Aurobinda. 2016. From a Latent to a Strong Soft Power? The Evolution of India's Cultural Diplomacy. Palgrave Communications, hlm.1-11 dapat diakses di https://www.nature.com/articles/palcomms201691.pdf

Nye, Jr., Joseph S. 2004. Soft Power The Means To Success in World Politics. New York : Public Affairs

Nye, Jr., Joseph S. 2008. Public Diplomacy and Soft Power. The Annals of the American Academy of Political Science. No.616, hlm.94-109

Paul, T.V. 2014. Indian Soft Power in a GloIndonesiazing World. Current History (New York, N.Y.: 1941) 113(762):157-162 dapat diakses di https://www.researchgate.net/publication/293349258_Indian_Soft_Power_in_a GloIndonesiazing_World

Putri, Melisa Indriana . 2015. Tayangan India dalam Industri Televisi Indonesia ( Studi Kasus tentang Komodifikasi pada Trend Program India Periode 20142015). Tesis pada Program Magister Ilmu Komunikasi, Fakultas Ilmu Sosial dan Ilmu Politik, Universitas Diponegoro Semarang

Invasi Mahabharata, 1 Oktober $2014 \quad$ diakses di https://www.viva.co.id/arsip/543697-invasi-mahabharata

Yusuf, A. Muri. 2014. Metode Penelitian Kuantitatif, Kualitatif, \& Penelitian Gabungan. Jakarta : Prenada Media Goup. 